\title{
ANÁLISIS LINGÜÍSTICO DE CHISTES DEL TIPO "¿CÓMO SE DICE 99 EN CHINO? CACHI CHEN"
}

\author{
Gilda Rosa Arguedas Cortés
}

\begin{abstract}
There are many types of jokes in tems of structure and topic; however, they all share the characterestic of being brief and that they are told with the purpose of provoking laughter. Besides showing the ingenuity and mastery of the person that tells them in terms of gestures, entonation and imitation, the purpose is to entertain the audience. This article analyses jokes with the structure "How do you say $\mathrm{x}$ in German, Chinese, Portuguese, Arab, etc.?" The answer corresponds to a gloss of the term, phrase or sentence in that language but since the person telling the joke does not know the language, he translates it using Spanish words with sounds, entonations and structures that sounds similar to the language in question.
\end{abstract}

\section{Introducción}

Según el Diccionario de la Real Academia Española, el chiste es un dicho o historieta muy breve que contiene un juego verbal o conceptual capaz de mover a risa.

El chiste es, junto con la hagiografía, la leyenda, el mito, el enigma, la sentencia, el caso, el acontecimiento memorable y el cuento fantástico, una de las formas fundamentales del arte verbal (Jolles, 1972).

0.1. Chistes hay de muchos tipos en cuanto a estructura y temas pero todos comparten las características de la brevedad y el de ser contados para producir risa, esto es, tienen la función, aparte de manifestar el ingenio y la maestría del cuentista en cuanto a ademanes, gestos, entonación e imitación, de divertir a la audiencia. Los chistes son muy variados. Hay sexuales, políticos, escatológicos, racistas, de oposiciones, de comparaciones, duelos verbales, obras de teatro ("Se abre el telón..."), imitación de extranjeros, etc.

0.2. Este trabajo se basa en el tipo de chistes que presenta la estructura " ¿Cómo se dice X en alemán, chino, portugués, etc?". La respuesta es la glosa del término, frase u oración en esa lengua. Por supuesto, el contador del chiste no conoce ese idioma y lo que hace es "traducir" usando palabras en español con sonidos, entonaciones y estructuras que recuerdan esa lengua. El éxito del chiste consiste en lograr que los oyentes, al compartir esa percepción de la lengua extranjera, lo entiendan y se rían. 
Este tipo de chistes no sólo se da en nuestra cultura hispana. Una estudiante canadiense me informó que en su cultura también se presentan.

El corpus se recogió en fiestas, reuniones informales, comidas y con los estudiantes universitarios; se utilizó también el Banco de datos de tradiciones orales y artes verbales del profesor Emilio Arias de la Escuela de Filología, Lingüística y Literatura de la U.C.R. Todos los informantes fueron costarricenses de diferentes edades y sexo con excepción de dos: un español y un mejicano. Ellos me indicaron que en sus países se cuentan estos chistes frecuentemente.

En general son "chistes de salón" ya que pueden contarse en cualquier sitio para una audiencia muy variada pues son bastante inofensivos. Hay, sin embargo, algunos de temas sexuales y escatológicos que podrían ofender a un conocido reciente o a una señora de edad mayor; pero los chistes, como es de todos conocido, se cuentan básicamente en reuniones de amigos con ánimo de divertirse.

0.3. Los extranjeros representados en estos chistes son los que, por razones de inmigraciones, han convivido con los hispanos durante bastante tiempo. Este estudio toma en cuenta a los que los costarricenses conocemos por ese motivo (chinos, italianos, árabes) o también por aparecer en películas (japoneses, africanos, alemanes) o en periódicos (rusos, vietnamitas), o en deportes como el fútbol (brasileños). El hacer chistes sobre estos grupos culturales manifiesta, si no xenofobia, al menos una actitud de desconfianza ante grupos de costumbres y aspecto físico diferentes y lenguas incomprensibles. En el caso de los chinos y de los negros, es muy frecuente oír en nuestro país el apelativo de "chinitos" o "negritos", con un matiz paternal y condescendiente.

0.4. Las lenguas que aparecen en estos chistes son el chino, japonés, alemán, árabe, portugués, italiano, griego, ruso, vietnamés, francés, latín y africano. En cuanto al chino, ya sabemos que no hay una lengua que se llame así; existen el mandarín, el cantonés, el taiwanés pero, para el hablante de español, chino es lo que hablan los chinos como grupo racial. Con el nombre de árabe se denomina la lengua de grupos como árabes, judíos, libaneses e iraníes.

En el caso del término africano se piensa en la lengua de cualquier negro de África, no en el swahili, bantú, hotentote o zulú. En todo caso, un costarricense nunca ha oído hablar a un africano, a no ser en las películas de Tarzán o de otras aventuras en ese continente.

El latín se conoce por la Iglesia Católica y su liturgia y por palabras que han quedado en el español como ángelus, méa culpa, currículum, memorándum o quórum.

Sobre Vietnam y el vietnamés nos enteramos por los periódicos, la televisión y el cine durante la guerra con los Estados Unidos. El alemán lo conocemos por películas de la Segunda Guerra Mundial, al igual que el japonés. El francés ha formado parte por muchos años del currículum de la Enseñanza Media en Costa Rica, lo mismo que el inglés.

El portugués se conoce principalmente por la transmisión de partidos de fútbol y entrevistas a jugadores brasileños, para algunos los mejores del mundo.

0.5. Es muy interesante que no haya chistes referidos al inglés y muy pocos al francés. Considero que hay dos razones básicas para que no se presenten.

En primer lugar, el lenguaje tiene dos planos: el plano de la expresión y el plano del contenido. La expresión es la estructura de sonido, esto es, los sonidos y sus ordenamientos especiales, y el contenido lo constituyen los significados que se transmiten por medio de esos sonidos. Cuando se oye una lengua extranjera desconocida uno está únicamente en contacto con el plano de la expresión (sonidos, entonaciones y grupos fónicos); el significado está vedado. 
Aprender una lengua extranjera es relacionar significados conocidos con sonidos y estructuras diferentes. Estos chistes lo que hacen es tomar sonidos, entonaciones y algunas estructuras de esas lenguas desconocidas, tan diferentes del español, y llenar con palabras de nuestra lengua ese plano del contenido al que no se tiene acceso. Eso es lo que produce el efecto cómico. En lenguas como el chino, el árabe, el japonés y el vietnamés, esto es muy fácil pues, por ser lenguas de familias linguísticas tan distintas a la nuestra, se pueden crear fácilmente glosas graciosas. De hecho, la mayor cantidad de chistes del corpus está en estas lenguas. En portugués e italiano, tan cercanos al español por su condición de lenguas romances, es más difícil glosar pues el significado se transparenta de alguna manera.

Los chistes recogidos en francés muestran un conocimiento formal de la lengua, con sus dos planos relacionados, debido a que se ha estudiado en el sistema escolar. El término "madame" se sabe que es señora y se usa para las profesoras de francés; la construcción "c'est" (este es, esta es) se emplea también en los chistes.

El inglés es muy conocido por la gente pues está en nuestro ambiente cultural (cine, música, revistas, televisión, deportes, marcas y propaganda de ropa, zapatos, vehículos, electrodomésticos). También los niños reciben actualmente enseñanza de esta lengua, ya no sólo en secundaria sino en el kinder y la primaria. Es muy díficil, en consecuencia, ponerle un sentido en español a expresiones fónicas que ya tienen su correspondiente significado, conocido por los hablantes.

La segunda razón para que no se den estos chistes en inglés es cultural. No vamos a hacer burla de una cultura a la que admiramos y quisiéramos de alguna manera pertenecer. Se usa ropa norteamericana, se oyen discos y se ven películas en inglés, se comen hamburguesas en Mc Donald's y Burger King y se sueña con ir a los Estados Unidos. Los grupos culturales en cuyos idiomas se tienen chistes se consideran minoritarios, raros, de costumbres curiosas y, por supuesto, no producen admiración y, en algunos casos, sólo tolerancia.

\section{Análisis del corpus}

Estos chistes presentan caracterísiticas de tipo fonético, léxico y sintáctico que hacen que los hablantes del español los interpreten como pertenecientes a una determinada lengua.

Los temas en todos los chistes versan sobre sexo, política, escatología, parentesco (especialmente la suegra), partes del cuerpo, prendas de vestir, vehículos, características humanas como tamaño, peso y actitudes de diferente tipo. Presentan onomatopeyas, ideófonos, metáforas, metonimia y sinonimia. El disfemismo se nota en el uso de términos fuertes y vulgares como jeta (boca), raja (vagina), preñar (embarazar), mear (orinar) y cagar (defecar).

En la escritura se usa una ortografía práctica; se marcan con tílde las vocales de las sílabas acentuadas y se unen las palabras que se pronuncian como grupos fónicos. La separación silábica en la pronunciación se señala con guiones. 


\subsection{Chistes en chino}

Los apellidos de la mayoría de los chinos en el país tienen la letra ch (Chang, Chen, Ching, Chung) y sonidos nasales. Además su idioma presenta varios sonidos de tipo palatal y nasal. Al hablar en español los chinos cambian la $\mathrm{r}$ por 1 y acortan las palabras.

Para representar el chino los hablantes hispanos usan los siguientes procedimientos:

a. Uso de palabras que presentan ch y $\mathrm{n}$ en español. vo -ón).

Hombre gordo: Chanchón (Chancho como sinónimo de gordo, con el sufijo aumentati-

Suegra: Cíncha.

Diputado: Chanchúllo.

En ambos casos se usan metáforas basadas en la similitud de función, la función es desvalorativa pues los hablantes consideran el referente con menos precio. Cincha: Faja con la que se asegura la silla o albarda sobre la cabalgadura (DRAE). Se manifiesta la idea de que la suegra es la encargada de mantener al yerno en su lugar, de controlarlo. Chanchullo: Voz familiar para manejo ilícito para conseguir un fin, y especialmente para lucrarse (DRAE).

Culo: Zanjón (Metáfora basada en la similitud de forma. Zanja con el sufijo aumentativo -ón)

Zopilote: Zóncho (Costarriqueñismo sinónimo de zopilote. Gagini dice que es apócope de zonchiche).

Se murió el perro: Canfín. (El fin del can =perro; juego con el término canfín: nafta, NDC).

Papel limpio: Chin manchón (Mancha con el aumentativo -ón).

Pelo sucio: Chin champú. NDC).

Moto Cross: Cáchi medespícho (Despicharse: destrozarse, despedazarse. Jerga juvenil,

El chiquito se cayó al agua: Chiquilín chupulún chún (Chiquilín: diminutivo de chico. Chupulún: ideófono que indica la acción de caer, de irse a un vacío; NDC. Chún: ideófono para la caída en el agua).

b. Sustitución de s por ch ( [ s ] - [t $]$ )

Enano, hombre pequeño o Pepe Figueres: Cáchi nonáche.

Minifalda: Che laví.

Huérfano: Chin chumádre.

Naúfrago: Chin chuláncha.

Me robaron la moto: Chin chuchúqui (Suzuqui: marca de motos).

Pobre: Chin unchínco.

Bomba: Háche púm (Púm: ideófono que indica explosión). 
c. Sustitución de r por 1

Mujer virgen: Chin plobál.

Mujer soltera o señorita: No plobó.

Mujer casada o señora: Yá plobó.

d. Pérdida de sílabas pretónicas

Espejo: Ái tói ió (Ahí estoy yo; hay cambio del acento en ahí.)

Ái tá (Ahí está).

Calzoncillo sucio: Tá untáo ( Está untado).

Mujer casada: Tá usáa.

Sin trabajo: Tói chín chámba ( Chamba: trabajo. Usada por hombres. NDC.)

e. Pérdida de la d en los participios pasivos

Mujer soltera: No tá usáa.

Mujer divorciada: Yá tá usáa.

Mujer recién casada: Tá chimáa. (Chimado: lesionado. Chimar: lesionar la piel a causa del roce, producir chima; NDC).

Viejita: Tá oxidáa. (El metal viejo se oxida).

f. Reducción de diptongos

99 : Cáchi chen (casi cien).

En el chiste ¿Cómo se dice el gato se cayó? Miáu se tún, hay un juego de palabras con Mao Tse-Tung, el famoso político chino. Tún es ideófono de la caída.

Hay un chiste que debe enunciarse con música y es un tipo de onomatopeya que recuerda el fondo musical de las películas de misterio o suspenso; presenta reduplicación:

¿Cómo se dice en chino misterio (o secreto)? Chán-cha-cha-chán.

Es interesante señalar que en los chistes en chino se producen características semejantes a las del habla infantilizada que es la forma de hablarles los adultos a los niños: ¿Chichí quére lechíta? ¿El chichí tá canchaíto?

Tal vez se deba a esa actitud paternalista que tienen los hablantes costarricenses para con los "chinitos", a la que hice ya referencia.

También son estas las mismas características fonéticas que se dan en la formación de hipocorísticos: Graciela-Ciela- Cela-Chela.

\subsection{Chistes en japonés}

Para el japonés se tiene una estructura de sílabas del tipo consonante-vocal; con la entonación y el acento se destacan estas sílabas separándolas, lo que produce un efecto cortante (tata-ta).

La presencia de la consonante oclusiva / t / y de la terminación ito, en palabras como Hirohito (el emperador de Japón), se manifiesta con el uso del sufijo diminutivo -it. La presencia 
de la consonante velar / $\mathrm{k} /$ es característica en nombres propios y marcas japoneses como Michiko, Masako, Tokio o Kawasaki. La "y" se presenta en Yamaha, Yamamoto, Fujimori, y Ajino-moto (pronunciada la j como y). Hay pérdida de la "d" del participio pasado y de sílabas pretónicas como para el chino pero no se da cambio de $\mathrm{r}$ en 1 porque se sabe que hay $\mathrm{r}$ en la lengua por palabras como Hiroshima e Hirohito.

Recién casada: Mi-quí-to chi-máo (De mico: órgano sexual femenino y chimado:

lesionado; NDC).

Bomba atómica o fin del mundo: Ni-cá-ca qué-a (queda).

Papel higiénico: Qui-tá ca-quí-ta.

Ministro de economía: Ni-có-mo ni-cá-go.

Sida: Ca-quí-ta que-má-ta.

Tu-cá-ca má-ta.

Te limpio la nariz: Te-sá-co tu-mó-co.

Dedo índice: Sá-ca-mó-co. (También se recogió para el chino con el cambio de s en ch (Cháca móco). tuberante).

Díaz Ordáz: Ho-ci-quí-to (Expresidente de México de dientes muy grandes y boca pro-

¡Qué susto!: Cá-si me cá-go. (Oración exclamativa sinónima).

Mujer guapa, rica: Tu-mí-co mecscí-ta. (De excitar).

Me robaron la moto: Ya-no-mí-ro ca-wa-sá-qui (Por la marca de motos Kawasaki).

No parquear motocicletas: A-llí-no-mó-to (Juego de palabras con el nombre del condimento Aji-no-moto, la j se pronuncia como y).

Mujer ardiente: Cu-lí-to sa-ca-llá-ma.

Me robaron mi moto: Yá-no-mí-ro mi-ya má-ja (Por la marca de motos Yamaha).

Presidente de los alcohólicos anónimos: Wis-qui-cí-to yo-no-tó-mo.

Luis Alberto Monge: Wis-qui-cí-to con-ye-lí-to (Expresidente de Costa Rica con fama de gustar del licor).

Estoy en el espejo: A-quí tói ( Aquí estoy).

Desmayo: Ata-quí-to (Ataque con el sufijo diminutivo -it).

Mariguana: Yo-si-fú-mo mó-ta (Mota: droga; jerga juvenil).

Menstruación : Tu-mí-co te-sú-da.

\subsection{Chistes en alemán}

Al hablante hispano el alemán le suena cortante y muy gutural. Esta condición la refleja con el uso de consonantes velares. Se utilizan las oclusivas sorda y sonora / k / y / g / y la fricativa / x / (jota). La $\mathrm{r}$ se pronuncia totalmente vibrante y la / b / oclusiva siempre. Los infinitivos del alemán terminan en "en" y esa condición se señala usando los verbos conjugados en 3era. persona plural.

Bus: Sú-ban es-trú-jen bá-jen.

Bailar apretado: Es-trú-jen, vie-jas. (Dado por un informante mejicano).

Lluvia: Gó-tas y gó-tas cá-en. 
Gó-tas cá-en.

Aguacero o tormenta: Más gó-tas cá-en.

Suegra: ¿Que la rí-fen! (Oración desiderativa en la que se trata a la suegra como un objeto que puede rifarse).

Limpiarse: Des-miér-den-sen. (Un informante lo dio para el danés pues dijo que sen significa 'hijo de' en los apellidos de esa lengua; Christiansen: hijo de Christian).

Luna de miel: Des-vír-guen-sen.

Bailar apretado: Es-trú-jen-sen.

En estos últimos tres chistes se presenta repetido el sufijo -n, indicador de 2 da. persona plural de respeto (ustedes). Como el hablante no siente que el verbo en imperativo con ustedes esté señalado (canten, jueguen, abran) por ser el verbo pronominal, repite el sufijo. Podría trasladarse -n al final (estrújense-estrújesen) pero probablemente para que se escuche mejor ese final "en", propio del alemán, se prefiere repetirlo.

\subsection{Chistes en vietnamés}

En Costa Rica seguramente nunca se ha oído a nadie hablar en vietnamés pero sí hemos visto y leído mucho sobre la guerra en Vietnam. Las palabras de esa región terminan en "ng" (escritura que probablemente refleje una nasal velar en esa posición) nh o n. Además, en Costa Rica, al menos en el Valle Central, la n y la m finales se pronuncian siempre como velares, lo que ayuda a dar esa misma impresión sonora. Palabras conocidas con ese sonido son Vietcong, Vietnam, Saigón, Mekong, Ho Chi Minh, Vietmihn.

Dientes grandes o Díaz Ordaz: Bien dien-tón.

Erección: Póing (Es ideófono de un resorte que se suelta; hay comparación del pene con un resorte).

Casa sin techo: Sin zinc (Con la c final pronunciada como g y no como k).

Resorte: Bóing o Toñoñón (Ideófono para un resorte que se mueve; en toñoñón hay reduplicación).

Algunos informantes dieron estos tres últimos chistes para el chino, quizá por la presencia de las enes.

\subsection{Chistes en árabe}

Los sonidos faríngeos del árabe el hablante hispano los representa con la / x / (jota). Hay palabras conocidas como Mohamed y rajá con ese sonido. También, como para el japonés y el alemán, separa las sílabas para dar una impresión cortante.

La presencia de la / b / puede explicarse porque en algunas lenguas semíticas no se da la oclusiva sorda / p /, sólo la sonora. Es frecuente escuchar cuando se imita a un judío, por ejemplo, el cambio de p en b: "un bedazo de biña". Podría también pensarse en el famoso Alí 
Babá. La presencia de la sh ([ $\left.\int\right]$ ) en uno de los chistes podría deberse a asociaciones con términos como sheik (en películas) y sha (de Irán). Además, es interesante señalar que la gente "sin saberlo" utilizó en la elaboración de estos chistes palabras provenientes del árabe: jeta, jarábe y ojalá.

Suegra: Ja-lá, ja-lá (Forma reduplicada. Jalar: irse, marcharse; NDC).

O-ja-lá ja-lá-ra (Ojalá: del árabe "y quisiera Dios"; DRAE).

Dale de comer al pajarito: Ba-já la-jáu-la.

Hacer el amor: Mo-já-me la rá-ja (Raja: hendidura; es disfemismo para vagina. Esta glosa se recogió también para luna de miel).

Beso: Sa-lí-va-vá sa-lí-va-vié-ne.

Sha-lí-va-vá sa-lí-va-vié-ne.

Mo-já-me la-jé-ta (Jeta: Término despectivo para la boca; NDC. Viene del árabe: hocico, pico, nariz; DRAE). NDC).

Vomitar (o vomitada): Ái va-la-jáma (Ahí va la jama. Jama: comida, jerga juvenil;

Nunca comí carne : Ja-má ja-mé ja-món (Jamás jamé jamón. Jamar: comer, jerga juvenil; NDC).

Remedio para la tos: Ja-rá-be (Del árabe: bebida; DRAE. Presenta incorporada la palabra árabe).

\subsection{Chistes en portugués}

La estructura del portugués que se representa es sustantivo complemento de sustantivo o sustantivo complemento de adjetivo. La preposición con el artículo masculino es "do" (del) pronunciado con o cerrada, por lo que el hablante hispano lo interpreta como du. Para el femenino plural se usa "das" (de las); sólo el informante español usó "das" en estos chistes, lo que parece indicar que conoce la lengua portuguesa. Todos los costarricenses usaron "du" aunque el sustantivo término fuera masculino, femenino o plural, con excepción de uno que empleó da. Hay frases conocidas como desayuno (café da manhã) o pantorrilla (barriga da perna), que presentan esta estructura.

La o final se pronuncia como u por su condición de vocal media cerrada en esa posición. Las terminaciones eiro, eira, oira aparecen en palabras portuguesas como Río de Janeiro, forasteiro, o guerreiro. Las terminaciones iño, iña del diminutivo aparecen en senhorinha y en los nombres de jugadores de fútbol del Brasil como: Zinho, Mazinho y Jorginho. El famoso futbolista Pelé se llama Edson Arantes do Nascimento (pronunciado nachiméntu) y su nombre es ampliamente conocido en el país.

Bigote: Felpúdu du mócu (Metáfora por función: el felpudo y el bigote recogerían la suciedad, en un caso barro o polvo y en el otro, mocos).

Féltru da náta (Metáfora basada en la similitud de aspecto del bigote y del fieltro: especie de paño no tejido que resulta de conglomerar borra, lana o pelo; DRAE. Cuando un hombre con bigote toma leche se le puede untar éste de nata). den comer).

Pulga: Pantéira du cáma (Metáfora por función, ambas son de temer porque nos pue- 
Tallador: Mecedóira du bólas.

Hamáca di pelotéiras.

Bola y pelota son sinónimos. Son metáforas por función; la mecedora, la hamáca y el tallador permiten que se meza su contenido; en un caso, las personas y en el otro, los senos. El uso de di en lugar de du indica una confusión con el italiano.

Calzoncillos: hamáca du bólas.

hamáca du boléiros.

hamáca du uóvo.

El término uóvo indica también una confusión con el italiano.

Lagartija: Cucudrílu das paréides (Cocodrilo, lagarto: reptil como la lagartija, pero muy grande).

Tetas: Cantína du béiby (Cantina: establecimiento, generalmente nocturno, donde se vende licor, adonde usan ir únicamente los hombres; NDC. Béiby, del inglés baby: niño de pecho; se usa en Costa Rica para los bebés y es término cariñoso entre enamorados).

Suegra: Feóla du nachiméntu.

Feiciña du nachiméntu.

(Fea de nacimiento = sustantivo complemento de adjetivo).

Silla giratoria: Secretáira du cadéiras movedízas.

Carrera (en el pelo): Camíño du pióyos. (La jota de piojos es pronunciada como y).

\subsection{Chistes en italiano}

Presentan una estructura similar a la de los chistes en portugués (sustantivo complemento de sustantivo). Estas frases son semejantes en español, portugués e italiano. La diferencia está en la contracción de la preposición y el artículo (del, du, di). En italiano aparece, pues, di: maceta (vaso di terra), cervecería (fábbrica di birra).

Lo que caracteriza al italiano es el alargamiento de las vocales acentuadas y su condición de vocales abiertas $[\varepsilon]$ y [ $\supset$ ]. También se alargan las consonantes para representar el efecto sonoro de las consonantes geminadas de esa lengua. Algunas palabras terminan en "i" pues esa vocal se escucha mucho en esa posición por indicar en italiano plural.

Bigote: Felpúudo di móoco

Zancudo: Avioóni di dormitóori (Metáfora por función: ambos vuelan)

Suegra: Freggoníissima (Fregar: molestar; es metonimia al decirse la cualidad, o defecto por la poseedora de él).

\subsection{Chistes en francés}

La principal característica es usar palabras agudas terminadas en "e". La acentuación del francés es básicamente aguda y muchos términos como los verbos en infinitivo de la primera conjugación, que son los más numerosos, terminan en el sonido "e" pues la r no se pronuncia (chanter=cantar). El diptongo "ua" se presenta pues recuerda palabras como François, moi, toi. 
La ñ existe también en francés. Hay que recordar que mucha gente conoce este idioma por el colegio.

Suegra: Madám metiché (Madame: Señora; el significado se conoce. Metiche o metiches: entrometido, voz despectiva; NDC).

Embarazada: Le preñé ( Preñar: disfemismo por embarazar).

Chico (o Paco), el playo: Fransuá, le sensualité.

Fransuá, le sensibilité (Fransuá=Francisco).

Un chiste de este tipo, un poco más largo, se lo escuché al ventrílocuo Coco Mora; en él se manifiesta el conocimiento del significado de la estructura francesa "c'est" (esta es) pero se emplea por terminar en "e":

¿Cómo se dice en francés?

Abuela: Cé labuelé

Hermana: Cé lermané

Tía: Cé la tié

Prima: Cé la primé

Mamá: Cé la ... ¡Mejor no sigo! (Mamar: chupar los órganos sexuales).

\subsection{Chistes en africano}

Lo que caracteriza a estos chistes es un efecto sonoro que recuerda los tambores. Se tiene el estereotipo de que los africanos se comunican por medio de tambores pues hemos visto esa escena en muchas películas. Esa impresión se da con el uso de consonantes oclusivas, sonoras o sordas ( / t /, / g /, / b /,/ d / ), acompañadas de "a" ó "u" y de nasales $(/ \mathrm{m} /, / \mathrm{n} / \mathrm{/g} /)$ para recordar los sonidos de los tambores: tan tan, gan gan, tun, tun (más grave). Se hace una división silábica muy marcada, reduplicaciones y repeticiones de las palabras para producir ese efecto entrecortado.

Olés a sudor: Tu-tú-fo me-túm-ba (Tufo: hedor. Tumbar: hacer caer o derribar a una persona o cosa ). reducidas).

Violación: Te-túm-bo la tán-ga (Tánga: calzón o vestido de baño de dimensiones muy

Me encanta tu vestido de baño: Tu-tán-ga me-túm-ba.

Hacer el amor: Hún-da-la, hún-da-la.

Baratillo: Gán-ga, gán-ga.

Hacer café: Pon-gáa-gua, pon-gáa-gua.

Cementerio: Túm-ba, túm-ba, túm-ba (La idea del plural túmbas se expresa con la repetición del término).

\subsection{Chistes en griego}

Lo que caracteriza al griego es la presencia de terminaciones como orba, escuchada en Zorba, el Griego (película y música famosas), y pulos, en apellidos griegos como Chryssopulos (en la Provincia de Cartago). 
La forma "papa" que se encuentra en tecnónimos (apellidos derivados del nombre del hijo) nos recuerda esa lengua pues aparece en apellidos de personas de origen griego como Papayorgo (Padre de Jorge) y Papastefanou (padre de Estéban).

Suegra: Es-tór-ba (Algunos informantes lo dieron para el ruso y uno para el alemán.)

Calderón: Pa-pa-ná-tas (Rafael Ángel Calderón: Expresidente de Costa Rica. Papanatas: tonto. Es una metonimia pues se dice el defecto por el poseedor. El sufijo -s tiene significado peyorativo y las palabras que lo llevan indican poco aprecio por el designado: cuilmas, milindres, mamitas).

Figueres: Pa-pa-ná-tas sin-es-crú-pu-los (José María Figueres: Presidente de Costa Rica).

\subsection{Chistes en ruso}

Para el ruso se usa la consonante / k / y las terminaciones "ska" y "of". La / k / aparece en términos rusos de diferente tipo: Kruschev, vodka, perestroika. El grupo "ska", que es un diminutivo en ruso, aparece en palabras como Ninoska (en películas) o los misiles Katiuska.

La terminación "of" acentuada aparece en apellidos o marcas como Orloff, Strogoff, Romanov, Gorbachov (/ v / pronunciada como [ f ] ) o en el lomito Stroganoff que ofrecen los restaurantes.

Sida: Tu cu-lóf me ma- tóf.

Pepe Figueres (o enano): Mi-rrús-ka. (José Figueres: expresidente de Costa Rica conocido por su pequeña estatura. Mirrusca: cosa diminuta, migaja, NDC.)

\subsection{Chistes en latín}

Sólo se recogió uno: ¿Cómo se dice llueve en latín? Án-ye-lus mean. (Mear: disfemismo por orinar). La palabra ángelus es muy conocida y la gente pronuncia la "ge" como "ye" pues esa es la pronunciación tradicional de los curas. La terminación "m" es frecuente en palabras latinas, pues es la marca del caso acusativo. La "m" final se pronuncia en Costa Rica, en el Valle Central, como la nasal velar [ $\mathrm{\eta}]$, al igual que la n (currículum, memorándum, quórum).

\section{Conclusión}

La creación de chistes en los que se emplea el habla extranjerizada es muy frecuente en nuestro país y pareciera que en otros también. En este análisis se trató de determinar las características fonéticas que debe presentar un enunciado para que el oyente lo considere como perteneciente a un determinado idioma.

Se descubrió que las lenguas de familias lingüísticas más lejanas a la del español son fuente de un mayor número de chistes. A pesar de esto considero que, si se explicitan las pautas que se siguen en su elaboración, podrían crearse muchísimos más chistes en cualquiera o en cualesquiera de las lenguas estudiadas. 
Para finalizar les presento la Organización del nuevo Gabinete Ministerial de la República del Perú.

Presidente: Al-bér-to Fu-yi-mó-ri

Vicepresidente: Mi-cá-go en-tu-má-re

Ministros:

De Alimentación y Abastecimiento: Ni-có-mo ni-cá-go.

Del Ejército: Ni-tí-ro ni-má-to.

De la Marina: Po-pó-co mia-ó-go

De Economía y Finanzas: Me-quéo- con-tó-o

Del Interior: Si-te-có-jo te-jó-do

De Vivienda: Te-quí-to ca-sí-ta

De Sanidad: Ma-chú-ca tu-cá-ca.

De Aviación: Chi-cái-go me-jó-do

De Comunicaciones: Ni-sé-lo-qui-pá-sa

De Transportes: Ya-mi-cá-yo no-ca-mí-na . (Cáyo: carro; la r fricativa del español de Costa Rica se interpreta como "y", como lo hacen los niños).

Secretaria: Qui-pú-ta qui-sói

\section{Bibliografia}

Jolles, André. 1972. Las formas simples. Santiago: Editorial Universitaria, S.A.

Kany, Charles E.1969. Semántica hispanoamericana. Argentina: Aguilar S.A. de Ediciones.

Quesada, Pacheco, Miguel Ángel. 1991. Nuevo Diccionario de Costarriqueñismos. San José: Editorial Tecnológica de Costa Rica.

Rodríguez Bolaños, Edgar. 1977. El lenguaje del grupo hampesco costarricense. Tésis de Licenciatura: Universidad de Costa Rica.

Diccionario de la Real Academia Española (DRAE). 